\title{
DA TUTELA DOS DIREITOS DO NASCITURO COM GESTANTE EM SITUAÇÃO DE RUA EM PERÍODO DE PANDEMIA E A DIGNIDADE HUMANA
}

\author{
Aimee Bortollo Petrocelli*1 \\ Cleide Aparecida Gomes Rodrigues Fermentão* ${ }^{2}$
}

RESUMO: Trabalho destinado à análise da proteção aos direitos do nascituro, sob o prisma da gestante em condição de rua. Abordagem da controvertida questão do início da personalidade do nascituro e verificação das teorias sobre a existência da personalidade civil. Discussão sobre os direitos salvaguardados por lei ao concepturo, como reflexos às garantias da gestante. Análise da condição das gestantes em situação de rua no Brasil, especialmente durante a pandemia da Covid19, e de como esse cenário afeta diretamente ao nascituro e aos seus eventuais direitos. Para tanto, desenvolve-se um ensaio teórico com investigação de bibliográfica e documental e abordagem teórico-doutrinária.

Palavras-Chave: Nascituro; Personalidade jurídica; Gestante em situação de rua; dignidade humana; pandemia.

\section{THE PROTECTION OF THE UNBORN CHILD'S RIGHTS AND THE PREGNANT WOMAN LIVING ON THE STREET DURING THE PANDEMIC AND HUMAN DIGNITY}

\begin{abstract}
This article is destined to analyze the protection of the unborn child's rights, from the perspective of the pregnant woman living on the street. Study of the controversial question of the beginning of unborn child's personality and the theories about the existence of the civil personality. Discussion of the rights safeguarded by law to the unborn child as a reflection of the pregnant woman's guarantees. Analysis of the condition of pregnant women living on the streets in Brazil, especially in Corona Virus pandemic, how this scenario affects the unborn child and their rights. Research method theoretical, bibliographic, documental and doctrinal.

Key words: Unborn child; Legal personality; Pregnant woman living on the street; Human dignity; Pandemic.

\footnotetext{
${ }^{1} *$ Mestranda em Ciências Jurídicas pelo Programa de Mestrado em Direito da UNIVERSIDADE CESUMARUNICESUMAR; Especialista em Direito Notarial e Registral pela Faculdade IBMEC - SP; graduada em Direito pela Universidade Estadual de Maringá - UEM; com endereço postal na Rua Benício Moreira Niza, n. 50, Centro, Mandaguaçu-PR e endereço eletrônico aimeepetrocelli29@gmail.com.

2 * Pós doutora em hermenêutica jurídica pela UNISINOS-|Universidade Vale dos Sinos-RS; Doutora em Direito das UEM-Universidade Estadual de Maringá; pesquisa do ICETI-Instituto de pesquisa da Unicesumar; Professora titular de direito no Programa de Mestrado e doutorado em direito, e na graduação em direito da UNIVERSIDADE CESUMAR- UNICESUMAR; membro do IBDFAM e do IAP-Instituto dos advogados do estado do Paraná. Advogada; com endereço postal na Avenida Doutor Gastão Vidigal, n. 1400, Zona 08, Maringá-PR e endereço eletrônico cleidefermentao@gmail.com.
} relações sociais pela UFPR-Universidade Federal do Paraná; Mestre em direito civil e graduada em direito pela
\end{abstract}




\section{INTRODUÇÃO}

Muito se discute na doutrina sobre a natureza jurídica do nascituro diante do direito positivo brasileiro, e a forma pela qual são ressalvados seus direitos, especialmente em razão da controvérsia se ele teria ou não personalidade para adquirir e defender seus próprios direitos ou depende de representação. Nessa perspectiva, o presente artigo desenvolver-se-á a partir de um bosquejo histórico, doutrinário e jurisprudencial, analisando as referidas controvérsias, buscando compreender o tema do nascituro e do início da personalidade jurídica, para que, com isso, seja possível delimitar quais direitos seriam contemplados ao ser humano desde a sua concepção.

Inicialmente serão apresentados os conceitos de nascituro e de personalidade jurídica. Após, será abordado o conflito relacionado à determinação do momento em que se inicia a vida e, por ainda não ter nascido, se o nascituro se encaixaria nesse contexto, detendo personalidade jurídica, ou não. Para que essa determinação ocorra, ou seja, na busca pela definição do momento em que se inicia a vida e, consequentemente, a personalidade jurídica dos indivíduos, a doutrina se divide em três principais correntes, quais sejam: natalista, concepcionista e da personalidade condicional, cujos posicionamento serão devidamente explanados. Após a análise das respectivas correntes, a partir de uma visão doutrinária e jurisprudencial do assunto, este trabalho abordará, por meio de uma análise do ordenamento jurídico como um todo, as garantias que eventualmente são resguardadas ao nascituro.

Ao longo do desenvolvimento da referida temática, perceber-se-á que todas essas questões estão diretamente relacionadas com a pessoa responsável pelo desenvolvimento do concepturo, que é a gestante. A ela devem ser garantidas condições mínimas para uma gestação saudável, porque seus direitos são reflexos ao do nascituro. Sem que aqueles sejam preservados é impossível falar na garantia destes. Esse cenário torna-se ainda mais complexo quando se trata de gestantes em condição de rua e no contexto da pandemia do Corona Vírus, pois essas mulheres compõem um grupo populacional praticamente invisível na sociedade, vivendo extremamente marginalizadas e em condição de miséria, sem amparo por parte do Estado e da sociedade, expondo-se e aos seus filhos à perigo de vida, tendo diariamente violados seus direitos subjetivos. 
O presente artigo buscará resposta à seguinte problematização: $\mathrm{O}$ nascituro, ao ser gerado em gestante em condições de rua, em período de pandemia, tem seus direitos e sua dignidade protegidos? Existem ações públicas a tutelarem o nascituro quando a gestante está em condição de rua e abandonada em sua própria condição de vulnerabilidade?

Para responder a tais questionamentos o presente artigo discutirá essa realidade brasileira e se existem políticas públicas adotadas no enfrentamento dessa situação, para tornar menos vulnerável a vida dessas gestantes em situação de rua, garantindo a preservação de seus direitos da personalidade, bem como de seus filhos que ainda carregam no ventre. E, é preservando os direitos dessas mulheres por meio do fornecimento do mínimo necessário para um gestação saudável, como saúde, higiene e alimentação, que o nascituro terá um desenvolvimento digno, com suas garantias preservadas. Só então será possível falar em direitos do nascituro.

O método a ser adotado na presente pesquisa será o dedutivo, e valer-se-á de referências bibliográficas, com leituras em artigos científicos, livros e jurisprudências.

\section{NASCITURO: NATUREZA JURÍDICA E TEORIAS DA PERSONALIDADE}

O estudo das pessoas, tema de destaque na Teoria Geral do Direito Civil, sempre gerou discussões e polêmicas perante os doutrinadores e juristas. E é nesse contexto que o nascituro se insere. Esta vida intrauterina, por nascer, ainda em período gestacional, segundo nosso ordenamento jurídico, já tem alguns direitos resguardados. Em razão disso, para alguns estudiosos, este ente é tratado como pessoa, dotada de personalidade jurídica; para outros, contudo, o nascituro não tem personalidade, mas apenas expectativa de direito, que só se concretiza com seu nascimento com vida. Diante disso, passa-se à analise desses conflitos doutrinários e jurisprudenciais concernentes à temática.

Pessoa é todo ente dotado de personalidade jurídica, sendo esta entendida como a aptidão genérica titularizar direitos e contrair obrigações na ordem jurídica. É o atributo necessário para ser sujeito de direito (BEVILÁQUA, 1927, apud GONÇALVES, 2014, p. 94). O início da personalidade da pessoa natural está estabelecido no Código Civil, em seu artigo $2^{\circ}$, que 
prevê: "a personalidade civil inicia com o nascimento com vida, mas a lei põe a salvo, desde a concepção, os direitos do nascituro". Portanto, da leitura do referido dispositivo legal, compreende-se que seria a partir da junção dos pressupostos nascimento e vida que se teria a personalidade jurídica.

$\mathrm{O}$ ordenamento jurídico brasileiro não define o início da existência da pessoa. $\mathrm{O}$ Conselho Nacional de saúde, entretanto, no art. 29, item 6, da Resolução 1, de 13.06.1988, prevê que o nascimento com vida ocorre com a expulsão completa do produto da concepção, tendo ele, após a separação, respirado e com batimentos cardíacos. Portanto, a ocorrência do elemento vida estaria condicionada à verificação do fenômeno fisiológico da respiração. Ocorre que nascituro, apesar de ser um ente já concebido, ainda não é nascido. Discute-se, em razão disso, se ele seria considerado um sujeito de direitos, dotado de personalidade jurídica, e, em caso positivo, quais seriam essas proteções a ele legalmente garantidas.

A doutrina, ao interpretar o artigo $2^{\circ}$ do Código Civil, retroexposto, visando delimitar o início da personalidade civil e se o nascituro estaria nesse contexto incluído, não se posiciona de forma pacífica, dividindo-se em três correntes: natalista, concepcionista e condicional. A teoria Natalista defende que a personalidade civil somente se inicia com o nascimento com vida. Dessa forma, o nascituro não é considerado pessoa, não goza de personalidade jurídica e, consequentemente, não titulariza direitos, visto que ainda não nasceu.

Explica o ministro Luis Felipe Salomão, no Recurso Especial n. 1.415.727 de Santa Catarina:

Pela teoria natalista, a personalidade jurídica só se inicia com o nascimento. Os adeptos dessa tese defendem que a titularização de direitos e personalidade jurídica seriam conceitos inexoravelmente vinculados, de modo que, inexistindo personalidade jurídica anterior ao nascimento, a consequência lógica é que também não há direitos titularizados pelo nascituro, mas mera expectativa. Os principais partidários da teoria natalista foram os comentaristas e doutrinadores clássicos do Código Civil de 1916, como Caio Mário da Silva Pereira, Sílvio Rodrigues, Eduardo Espínola e Vicente Ráo ${ }^{3}$.

${ }^{3}$ BRASIL. Superior Tribunal de Justiça. Recurso Especial: REsp. n ${ }^{\circ} 1.415 .727$ - SC (2013/0360491-3). Direito Civil. Acidente automobilístico. Aborto. Ação de cobrança. Seguro obrigatório. DPVAT. Procedência do pedido. Enquadramento jurídico do nascituro. Art. $2^{\circ}$ do Código Civil de 2002. Exegese sistemática. Ordenamento jurídico

\section{Revista Brasileira de Direito Civil em Perspectiva | e-ISSN: 2526-0243 | Encontro Virtual |} v. 7 | n. 1 | p. $24-44$ | Jan/Jul. 2021. 
A teoria da personalidade condicional, por vez, entende que a personalidade tem início a partir da concepção, mas o nascituro titulariza direitos submetidos a condição suspensiva, ou direitos eventuais. Fica submetida, dessa forma, a uma condição suspensiva, que é o nascimento com vida, no entanto, são assegurados, desde a concepção, os direitos da personalidade, inclusive para garantir o nascimento desse ser em formação.

Washington de Barros Monteiro (2001, apud GONÇALVES, 2014, p. 104), sintetiza o posicionamento dessa corrente, ensinando:

Discute- se se o nascituro é pessoa eventual, cidadão em germe, homem em spem. Seja qual for a conceituação, há, para o feto, uma expectativa de vida humana, uma pessoa em formação (...) o nascituro é pessoa condicional, a aquisição da personalidade acha- se sob a dependência de condição suspensiva, o nascimento com vida.

Para essa corrente, a personalidade começa com a concepção, momento em que são garantidos somente os direitos básicos. A vida, depende de evento futuro e incerto, que é o nascimento com vida, para consolidar a capacidade jurídica e os demais direitos. Ou seja, o nascimento com vida consolida direitos que estavam suspensos ao nascituro. A teoria concepcionista, por fim, afirma que a personalidade é adquirida com a concepção, ressalvados os direitos patrimoniais, que somente serão adquiridos a partir do nascimento com vida.

Maria Helena Diniz (2002, p. 113), adepta dessa teoria, defende que "o nascituro, tem resguardado, normativamente, desde a concepção, os direitos, porque a partir dela passa a ter existência e vida orgânica e biológica própria, independente da de sua mãe. Se as normas o protegem é porque tem personalidade jurídica".

Silmara Chinelato e Almeida (2000, p. 81, apud ARAÚJO; FILHO, 2007, p. 37-38) elucida que, diferente da teoria condicional, para a corrente concepcionista:

A personalidade do nascituro não é condicional; apenas certos efeitos de certos direitos dependem do nascimento com vida, notadamente os direitos patrimoniais materiais, como a doação e a herança. Nesses casos, o nascimento com vida é

que acentua a condição de pessoa do nascituro. Vida intrauterina. Perecimento. Indenização devida. Art. $3^{\circ}$, inciso I, da Lei n. 6.194/1974. Incidência. Recorrente: Graciane Muller Selbmann. Recorrido: Seguradora Líder dos Consórcios de Seguro DPVAT S/A. Relator: Ministro Luis Felipe Salomão. DJ: 04/09/2014.

Revista Brasileira de Direito Civil em Perspectiva | e-ISSN: 2526-0243 | Encontro Virtual | v. 7 | n. 1 | p. $24-44$ | Jan/Jul. 2021. 
elemento do negócio jurídico que diz respeito à sua eficácia total, aperfeiçoandoa.

A despeito da controvérsia acerca do momento em que se inicia a personalidade jurídica, apesar da literalidade do art. $2^{\circ}$ do Código Civil, que condiciona sua aquisição ao nascimento, infere-se de uma interpretação lógicosistemática do ordenamento jurídico brasileiro que a teoria prevalecente é a concepcionista. Inclusive é esse o entendimento que prevalece na jurisprudência ${ }^{4}$. Isso é necessário para que o nascituro tenha preservada a sua dignidade,

${ }^{4}$ RECURSO ESPECIAL. DIREITO SECURITÁRIO. SEGURO DPVAT. ATROPELAMENTO DE MULHER GRÁVIDA. MORTE DO FETO. DIREITO À INDENIZAÇÃO. INTERPRETAÇÃO DA LEI No 6194/74. 1 Atropelamento de mulher grávida, quando trafegava de bicicleta por via pública, acarretando a morte do feto quatro dias depois com trinta e cinco semanas de gestação. 2 - Reconhecimento do direito dos pais de receberem a indenização por danos pessoais, prevista na legislação regulamentadora do seguro DPVAT, em face da morte do feto. 3 - Proteção conferida pelo sistema jurídico à vida intra-uterina, desde a concepção, com fundamento no princípio da dignidade da pessoa humana. 4 - Interpretação sistemático-teleológica do conceito de danos pessoais previsto na Lei $\mathrm{n}^{\circ} 6.194 / 74$ (arts. $3^{\circ}$ e $4^{\circ}$ ). 5 - Recurso especial provido, vencido o relator, julgando-se procedente o pedido (STJ, REsp. N N $^{\circ} 1.120 .676$ - SC (2009/0017595-0), Relator Ministro Paulo de Tarso Sanseverino, DJ. 07.12.2010; grifo nosso)

AÇÃO DE COBRANÇA - SEGURO OBRIGATÓRIO DPVAT- MORTE -NASCITURO - DIREITO À INDENIZAÇÃO - CASO EM QUE A SOLUÇÃO DA LIDE DIZ RESPEITO À EXISTÊNCIA DO NASCITURO ENQUANTO PESSOA - INTELIGÊNCIA DO ARTIGO $2^{\circ}$ DO CÓDIGO CIVIL - PRECEDENTES DESTA TRU E DO STJ - SENTENÇA PARCIALMENTE REFORMADA. 1. O artigo $\mathbf{2}^{\circ}$ do Código Civil dispõe que "a personalidade civil da pessoa começa do nascimento com vida; mas a lei põe a salvo os direitos do nascituro". Assim, havendo lide relacionada a direitos de personalidade, não tem o nascituro somente expectativa de direitos, sendo, no tocante aos mesmos, de forma efetiva, sujeito de direito. Todos os fatos relacionados à sua vida, desde o momento da concepção, geram consequências jurídicas. No caso em tela, impedida a vida extrauterina, fato incontroverso, legítima a pretensão de recebimento da indenização. 2. Neste sentido julgado da então Turma Recursal Única sob a relatoria da Juíza ANA PAULA KALED A. ROTUNNO: EMENTA: RECURSO INOMINADO. DPVAT. MORTE NASCITURO. DIREITO À INDENIZAÇÃO. VALOR CONTIDO NA LEI 11.482/2007. CORREÇÃO MONETÁRIA A PARTIR DO AJUIZAMENTO DA AÇÃO E JUROS MORATÓRIOS A PARTIR DA CITAÇÃO. APLICAÇÃO DOS ENUNCIADOS 9.3 2 (2 $2^{\mathrm{a}}$ PARTE), 9.7 E 9.8 DA TRU. SENTENÇA MANTIDA POR SEUS PRÓPRIOS FUNDAMENTOS. 1. DECISÃO: Ante o exposto, a Turma Recursal Única resolve, por unanimidade de votos, CONHECER e NEGAR PROVIMENTO ao recurso, nos exatos termos deste voto." 3. Sobre o tema também se pronunciou o STJ: "RECURSO ESPECIAL. DIREITO SECURITÁRIO. SEGURO DPVAT. ATROPELAMENTO DE MULHER GRÁVIDA. MORTE DO FETO. DIREITO À INDENIZAÇÃO. INTERPRETAÇÃO DA LEI No 6194/74. 1 - Atropelamento de mulher grávida, quando trafegava de bicicleta por via pública, acarretando a morte do feto quatro dias depois com trinta e cinco semanas de gestação. 2 - Reconhecimento do direito dos pais de receberem a indenização por danos pessoais, prevista na legislação regulamentadora do seguro DPVAT, em face da morte do feto. 3 - Proteção conferida pelo sistema jurídico à vida intra-uterina, desde a concepção, com fundamento no princípio da dignidade da pessoa humana. 4 - Interpretação sistemático-teleológica do conceito de danos pessoais previsto na Lei $\mathrm{n}^{\circ}$ 6.194/74 (arts. $3^{\circ}$ e $4^{\circ}$ ). 5 - Recurso especial provido, vencido o relator, julgando-se procedente o pedido. (REsp 1120676/SC, Rel. Ministro MASSAMI UYEDA, Rel. p/ Acórdão Ministro PAULO DE TARSO SANSEVERINO, TERCEIRA TURMA, julgado em 07/12/2010, DJe 04/02/2011). Recurso conhecido e desprovido. Diante do exposto, resolve esta Turma Recursal, por unanimidade de votos, conhecer do recurso e, no mérito, negar-lhe provimento, nos exatos termos do voto (TJPR - $2^{\mathrm{a}}$ Turma Recursal - 0004780-45.2011.8.16.0173 - Umuarama - Rel.: Juiz Telmo Zaions Zainko - J. 26.01.2012; grifo nosso)

Revista Brasileira de Direito Civil em Perspectiva | e-ISSN: 2526-0243 | Encontro Virtual | v. 7 | n. 1 | p. $24-44$ | Jan/Jul. 2021. 
"qualidade intrínseca e distintiva de cada ser humano que o faz merecedor de respeito e consideração por parte do Estado e da comunidade, implicando, nesse sentido, um complexo de direitos e deveres fundamentais que asseguram a garantia das condições existenciais mínimas para uma vida saudável" (ALVES, 2016, p. 7).

Ainda que não se vislumbre a pacificação de entendimento a respeito da situação do nascituro, é inegável a existência de um sistema normativo de proteção abrangente, que contempla a pessoa por nascer. Inclusive, esse é o entendimento do Superior Tribunal de Justiça, no Recurso Especial n. 1.170.239 do Rio de Janeiro:

É certo que o nascituro, compreendido como o ser já concebido, mas ainda inserido no ventre materno, por guardar em si a potencialidade de se tornar a pessoa humana, é merecedor de toda proteção do ordenamento jurídico, destinada a garantir o desenvolvimento digno e saudável no meio intrauterino e o consequente nascimento com vida 5 .

Portanto, independente da corrente a que se filiem, é unanime o entendimento segundo o qual o nascituro merece proteção jurídica, titularizando, sim, alguns direitos compatíveis com sua condição de ser já concebido, mas ainda inserido no meio intrauterino.

\section{DIREITOS DO NASCITURO}

Conforme exposto no tópico anterior, é unanime o entendimento segundo o qual o nascituro merece proteção jurídica, que lhe garanta um desenvolvimento gestacional digno e saudável e consequente nascimento com vida.

O Código Civil, inclusive, na parte final do artigo $2^{\circ}$, é expresso ao prever que a lei põe a salvo, desde a concepção, os direitos do nascituro. Sobre esse artigo, o ministro Luis Felipe Salomão, do Superior Tribunal de Justiça (STJ), esclareceu no Recurso Especial n. 1.415.727 de Santa Catarina, que:

\footnotetext{
${ }^{5}$ BRASIL. Superior Tribunal de Justiça. Recurso Especial: REsp. n ${ }^{\circ}$ 1.170.239 - RJ (2009/0240262-7). Recursos Especiais. Ação de indenização por danos morais, decorrentes de exame médico, cujo resultado indicou, erroneamente, ser o feto portador de "Síndrome de Down" - Transação celebrada entre um dos devedores solidários e os demandantes - Instâncias ordinárias que condenaram o codevedor solidário ao pagamento de indenização aos pais, excluída a hipótese de reparação à filha, então nascituro à época dos fatos. Insurgência dos demandantes e da operadora de plano de saúde. Recorrente: Luciana Couto Sanches e Outros. Recorrido: Golden Cross Assistência Internacional de Saúde LTDA. Relator: Ministro Luis Felipe Salomão. DJ: 21/05/2013. Revista Eletrônica.
} 
A despeito da literalidade do art. $2^{\circ}$ do Código Civil - que condiciona a aquisição de personalidade jurídica ao nascimento -, o ordenamento jurídico pátrio aponta sinais de que não há essa indissolúvel vinculação entre o nascimento com vida e o conceito de pessoa, de personalidade jurídica e de titularização de direitos, como pode aparentar a leitura mais simplificada da $1 \mathrm{li}^{6}$.

O nascituro, portanto, mesmo que ainda não nascido, titulariza todos os direitos imprescindíveis para que venha, em condições dignas, a nascer vivo. A Constituição Federativa de 1988, apesar de não tratar dos direitos do nascituro de forma direta, aborda a temática implicitamente a partir dos direitos fundamentais, como a dignidade da pessoa humana (art. $1^{\circ}$, III) e o direito à vida (art. $5^{\circ}$, caput), e dos direitos sociais e previdenciários de proteção à gestante (art. $7^{\circ}$, XVIII e art. 201, II).

A proteção à vida humana, desde o seu nascedouro, ou seja, da concepção, até o surgimento da pessoa natural, com o nascimento com vida, é reflexa, decorrente da proteção que o ordenamento jurídico confere à Pessoa natural. Esta é o centro de imputação de todos os direitos e deveres na ordem jurídica, que tem por norte o Princípio da Dignidade da Pessoa Humana, erigido pela nossa Constituição Federal como o fundamento da República Federativa do Brasil. Dignidade é, portanto, a base de todos os direitos, internos e internacionais. A ciência do Direito e toda construção jurídica devem estar alinhados a essa proteção integral à vida do ser humano, que deve, inclusive, guiar e fundamentar as relações regidas pelo direito civil. Nesse sentido, como reflexo do princípio da dignidade da pessoa humana, são os direitos da personalidade. Previstos nos artigos 11 a 21 do Código Civil, estes "abrangem todas as situações jurídicas existenciais que se relacionam, de forma indissociável, aos atributos essenciais do ser humano"7.

Chavenco e Oliveira (2012, p. 661) ensinam que:

Os direitos da personalidade não são todos direitos irrestritos, mas sim os direitos subjetivos, os direitos essenciais cuja função seja garantir o mínimo necessário e imprescindível de uma vida com dignidade. Os direitos da personalidade representam os limites impostos tanto ao arbítrio do poder público como aos particulares que devem ser respeitados a fim de que a pessoa humana possa se

\footnotetext{
${ }^{6}$ BRASIL. Superior Tribunal de Justiça. Recurso Especial: REsp. n 1.415 .727 - SC (2013/0360491-3). Op. cit.

${ }^{7}$ BRASIL. Superior Tribunal de Justiça. Recurso Especial: REsp. n o 1.170.239 - RJ (2009/0240262-7). Op. cit.
} 
desenvolver e crescer como ente, na sociedade em que vive, e por isso mesmo, merece uma tutela específica do direito.

De acordo com a doutrina moderna, não há um rol taxativo de tais direitos. O que se tem é uma cláusula geral de tutela da pessoa humana, que encontra fundamento no princípio da dignidade da pessoa humana, norteador do Estado democrático de direito, que permite ao magistrado conferir proteção aos bens jurídicos relevantes a cada caso concreto (cf. art. $5^{\circ}, \mathrm{CF}$ ).

Nesse sentido, Casali (2004, p. 67) defende que:

Existem sim, direitos reconhecidos protegidos (...), antes mesmo do nascimento. Logo, caberá ao juiz, diante das controvérsias apresentadas, partir de um parâmetro essencial, adotado pelo Brasil da proteção integral, desde a concepção, devendo o Judiciário em seus julgados partir dessa premissa.

O Superior Tribunal de Justiça entende que "é certo que o nascituro, ainda que considerado como realidade jurídica distinta da pessoa natural, é, igualmente, titular de direitos das personalidade (ao menos, reflexamente)" (REsp. 1.170.239 - RJ). Assim, o período em que o feto permanece no ventre materno, como etapa primordial e primária da vida humana, deve ser resguardado pelo direito, favorecendo e propiciando a eclosão da pessoa natural, a partir de um mínimo de assistência material e moral. É o nascituro, portanto, detentor dos direitos da personalidade, compreendidos como a vida (que, no meio intra-uterino, deve ser propiciada por meio de assistência pré-natal, de alimentos gravídicos e as demais condições para um desenvolvimento gestacional saudável), a honra, a imagem, o nome, etc.

Para além das previsões constitucionais e do Código Civil, o Estatuto da Criança e do Adolescente também resguarda direitos ao nascituro. Em seu artigo $7^{\circ}$, o referido Estatuto garante à criança, inserido neste conceito o nascituro (cf. artigo $2^{\circ}$ do ECA), proteção à vida e à saúde, garantindo-lhe um nascimento e desenvolvimento sadio, em condições dignas de existência. $\mathrm{O}$ artigo $8^{\circ}$ do mesmo diploma legal também tutela o nascituro por meio da garantia de atendimento médico pré e perinatal à gestante, e somente por meio deste atendimento que se poderia atingir ao desenvolvimento saudável do feto. 
No mesmo sentido é a jurisprudência do Superior Tribunal de Justiça (STJ), em que no Recurso Especial n. 1.415.727 de Santa Catarina ${ }^{8}$, o ministro Luis Felipe Salomão ressalta que é garantida aos ainda não nascidos a possibilidade de receber doação (artigo 542 do CC) e de ser curatelado (artigo 1.779 do CC), além da especial proteção do atendimento pré-natal (artigo $8^{\circ}$ do Estatuto da Criança e do Adolescente), alimentos gravídicos (Lei n. 11.804/2008), cuja titularidade é, na verdade, do nascituro e não da mãe.

Sobre os alimentos gravídicos, estes abrangem valores suficientes para cobrir as despesas do período gestacional, da concepção ao parto, incluindo assistência médica, exames, internações, medicamentos, parto, comida, entre outras prescrições preventivas e terapêuticas indispensáveis à gestante. Embora sejam concedidos à gestante, de forma a evitar que a mulher grávida fique abandonada, sem qualquer auxílio material durante a gestação, verifica-se que a lei tutela indiretamente os direitos do nascituro, indivíduo que, no estágio fetal de vida, não possui condições suficientes para reivindicar seus direitos, fazendo-o através de sua mãe.

Percebe-se, ante o exposto, que o ordenamento jurídico como um todo assegura direitos ao nascituro. Vale ressaltar, contudo, que quanto aos direitos patrimoniais, o nascituro possui mera expectativa, que somente se concretiza, incorporando-se esses bens em seu patrimônio jurídico na hipótese deste ente vir a nascer com vida. Caso tal condição não se verifique, não há falar em incorporação ao patrimônio jurídico do nascituro de direitos patrimoniais. Tais direitos, são a única exceção, sendo que os demais direitos, relacionados à personalidade do nascituro, são lhe garantidos desde a concepção, como forma de preservar sua subjetividade, dignidade, respeito e consideração, por parte do Estado e da sociedade, tendo garantidas condições existenciais mínimas para uma vida saudável.

Sabe-se, contudo, que em razão de se encontrar em estágio fetal, mesmo sendo titular de direitos da personalidade e de direitos potenciais e tendo capacidade para demandá-los em juízo, o nascituro precisa de representação para tanto. A legitimidade para fazer valer suas garantias será possível apenas se houver representação por parte da mãe, ou de um curador, denominado de curator ventris (CHAVENCO, OLIVEIRA, 2012, p. 663). Outra consequência decorrente de sua

\footnotetext{
${ }^{8}$ BRASIL. Superior Tribunal de Justiça. Recurso Especial: REsp. n o 1.415.727 - SC (2013/0360491-3). Op. cit.
} 
condição de ente intrauterino é que, apesar de ser uma vida individual, com carga genética própria, o nascituro tem seus direitos intimamente ligados à gestante. Sem ela, garantias basilares como vida, saúde e dignidade do nascituro, tornam-se irrealizáveis. O bem estar da gestante e a preservação de sua dignidade são, portanto, condições vitais para o regular desenvolvimento fetal. Preservar os direitos dessa mãe é, reflexamente, garantir ao nascituro um desenvolvimento digno e saudável e o consequente nascimento com vida. Se a lei põe a salvo os direitos do nascituro desde a concepção, é de se considerar que o seu principal direito consiste no direito à própria vida e esta seria comprometida se à mãe necessitada fossem recusados os recursos primários à sobrevivência do ente em formação em seu ventre (PEREIRA, 2006, p. 517-519, apud LOMEU, 2008).

Ocorre que nem sempre esse mínimo para uma vida e desenvolvimento gestacional saudável é garantido a essas mulheres grávidas, que, em muitos casos, especialmente quando se fala daquelas em situação de rua, vivendo em condição de miséria e cujas mazelas foram intensificadas com a pandemia do Corona Vírus, sequer possuem alimentação ou o mínimo para sustentarem a elas próprias, que dirá para prover ao sustento do indivíduo em formação em seu ventre e um acompanhamento pré-natal de qualidade.

Essa realidade, que será abordada no tópico seguinte, acaba colocando-as e ao concepto em risco, ante a ausência de condições suficientes para um desenvolvimento sadio e digno, sendo necessárias implementações de medidas por parte do Estado e da comunidade a fim de solucionar essa problemática, protegendo e garantindo um mínimo existencial à gestante para que, consequentemente, seja o nascituro e seus direitos resguardados.

\section{GESTANTES EM SITUAÇÃO DE RUA}

Pessoa em situação de rua é aquela que não tem uma moradia fixa, pernoitando pelos espaços públicos da cidade, como praças, calçadas, baixos de viadutos, terrenos baldios, etc., bem como que pernoita em albergues ou abrigos, públicos ou privados (São Paulo; FIPE, 2000, p. 05).Na última década, o empobrecimento progressivo da população, acentuado com a pandemia do Corona Vírus, contribuiu para o aumento do número de pessoas que vivem em condição de 
rua, que "expõe o sujeito ao enfrentamento de carências de toda ordem, além de exigir que, ao mesmo tempo, ele se adapte a outras referências de vida social bastante distinta daquelas anteriormente vividas", a fim de garantir sua sobrevivência (VIEIRA; BEZERRA; ROSA, 2004, p. 26).

Dados do Instituto de Pesquisa Econômica Aplicada - IPEA apontam que o número de pessoas em situação de rua no Brasil cresceu 140\% (cento e quarenta por cento) entre 2012 e março de 2020, chegando a mais de 222 (duzentas e vinte e duas) mil pessoas (IPEA, 2020). No estudo "Populações em Situação de Rua em Tempos de Pandemia: Um Levantamento de Medidas Municipais Emergenciais", o referido Instituto, ainda, alerta para um aumento da população em situação de rua durante a pandemia, mesmo com ações emergenciais realizadas pelas prefeituras, especialmente por conta da desocupação crescente e mais intensa devido aos problemas econômicos. O referido estudo também reforça que "a necessidade de isolamento social e higiene para quem não tem sequer moradia (ou dispõe de residências provisórias coletivas) e a limitação repentina e severa dos já precários meios de sobrevivência (doações e pequenos serviços), aprofundam o abismo social que esse grupo vivencia” (IPEA, 2020).

Essa situação de vulnerabilidade social, lastreada pela miséria, abandono e violência, com ruptura dos laços que inserem esses indivíduos no trabalho e nas relações sociais, bem como pela fragilização física e mental dos mesmos, acaba por tornar essa realidade ainda mais complexa quando se trata de mulheres em situação de rua.

A experiência de mulheres em condição de rua possui especificidades que não atingem os homens que vivem na mesma situação. Isso decorre especialmente de aspectos microestruturais, como violência doméstica, sofrimento mental, drogadição, relações de gênero, maternidade e cuidado dos filhos, tudo isso somado à ausência de um lar. Segundo Frangella (2004, p. 197), "(...) mulheres sozinhas são, na maioria das vezes, compartilhadas por vários parceiros do agrupamento. Elas estão sempre expostas a estupros, apanham dos parceiros, que agem sozinhos ou em grupos". Essa realidade, acompanhada da invisibilidade social e do não uso de métodos contraceptivos, faz com que a gravidez seja uma possibilidade cotidiana. 
A professora da Faculdade de Direito da Universidade Federal de Minas Gerais e coordenadora da Escola de Formação em Direitos Humanos do Polos de Cidadania da UFMG, Marcella Furtado, aponta que as mulheres em situação de rua engravidam quatro vezes em média, enquanto a média das mulheres brasileira em geral é de 1,9 gravidezes.

Um estudo realizado no Rio de Janeiro por Almeida e Quadros (2016, p. 229), durante seis meses, com mulheres usuárias de drogas e em situação de rua demonstrou que, das 180 (cento e oitenta) entrevistadas, $92 \%$ (noventa e dois por cento) delas afirmaram já ter engravidado ao menos uma vez. Desse total, apenas 11 (onze) informaram nunca terem engravidado, 5 (cinco) não souberam responder e apenas $33 \%$ (trinta e três por cento) confirmaram terem feito o exame pré-natal, ao menos uma vez, durante a gestação. Costa et al. (2015) explicam que, nesses casos: A gravidez pode ser considerada um fator de risco social na esfera da saúde pública e um reforço à marginalidade e pobreza. Assim, no caso da gestação em situação de rua pode-se identificar a possível precariedade das condições de vida e a dificuldade de acesso aos serviços como fatores de risco para mãe e bebê."

A dificuldade de acesso aos serviços de atenção básica decorre, principalmente, da atuação territorial dos mesmos. Um estudo do IPEA aponta que, em que pese a população de rua conte com serviço específico, chamado "Consultório na Rua", estratégia constituída por equipes multiprofissionais da área de saúde que fazem atendimento fixo ou móvel para pessoas que se encontram nessa condição, oferecendo atenção integral à saúde, a maioria das cidades brasileiras não possui esse serviço itinerante. Em 2018, havia 152 equipes em 105 municípios, aquém do contingente elegível de 307 equipes em 262 municípios. (...) Embora presente em quase todo o território nacional (exceto em Roraima), verifica-se que a presença dessa estratégia ainda é limitada - apenas cinco estados contam com dez ou mais equipes de Consultório na Rua (MEDEIROS; CAVALCANTE, 2018, p. 756, apud IPEA, 2020).

As gestantes em situação de rua, que não possuem um local determinado de fixação, acabam não se vinculando a um centro de saúde específico, deixando de ter um acompanhamento pré-natal contínuo, bem como outras assistências, como segurança alimentar, orientação sexual, prevenção de doenças sexualmente transmissíveis, amamentação materna, etc. A população em 
situação de rua, em tese, tem direito e livre acesso a todas as políticas públicas de saúde. No entanto, o acesso desses indivíduos não raro é limitado por fatores como preconceito e exigências inadequadas (Carvalho, 2013; apud IPEA, 2020). Por exemplo, até 2011, a ausência de endereço constituía-se em impeditivo para emissão do Cartão Nacional de Saúde (Cartão SUS) e, muitas vezes, consequentemente o acesso ao sistema de saúde. Mesmo com a vigência de portaria disciplinando o atendimento a este público, os usuários ainda enfrentavam dificuldades de acesso, atribuídas ao desconhecimento da rede sobre a liberação do atendimento sem o cartão SUS ou mesmo pela falta de documentação individual (Miranda, 2017, apud IPEA, 2020).

É preciso que essa população, especialmente de mulheres, gestantes, vivendo nas ruas, tenha informação e o acesso facilitado aos serviços de saúde, que devem atender de forma fixa e móvel, atuando articulados com as unidades de saúde básica e com os centros de atenção psicossocial (Caps), de maneira a efetivamente assistir essas mulheres em um período tão importante em que duas vidas estão expostas à riscos, em situação de extrema vulnerabilidade.

Outro reflexo dessa falta de políticas públicas está no uso de drogas e consumo de álcool, presentes de forma geral na vida dos moradores de rua e que permanecem durante o período gestacional. Essas substâncias "minimizam os problemas que esse grupo enfrenta, como frio, fome, dor, sono, desconforto e humilhação" (COSTA et al., 2015). Por isso, a interrupção do uso torna-se um desafio, tanto pelo vício quanto pelo contexto em que essas pessoas estão inseridas.

Além da falta de acesso ao sistema de saúde e do uso de substâncias psicoativas, outro aspecto que afeta diretamente a saúde neonatal é a alimentação materna. O desenvolvimento do concepto depende diretamente do estado nutricional da gestante. Ocorre que, pela primeira vez em dezessete anos, mais da metade da população brasileira, ou seja, aproximadamente 125 (cento e vinte e cinco) milhões de pessoas, vivem insegurança alimentar, que é a incerteza de que terá comida na mesa. É como se a cada dez famílias, seis enfrentassem essa realidade. Essa situação é mais um reflexo da pandemia da Covid-19, que levou milhões de brasileiros à miséria ante os impedimentos de trabalho, principalmente no mercado informal (COSTA, 2021). 
Sendo esse o cenário geral, evidente que a situação agrava-se quando se trata das gestantes em situação de rua, que não têm uma alimentação adequada, quiçá algo para comer, vivendo, na maioria das vezes, em estado de desnutrição. Esse inadequado aporte energético da gestante pode levar a uma competição entre a mãe e o feto, limitando a disponibilidade dos nutrientes necessários ao adequado crescimento fetal, impactando diretamente no feto e em seu desenvolvimento futuro.

A alimentação, portanto, influencia diretamente na qualidade de saúde do feto. Durante o primeiro trimestre gestacional, a saúde do embrião depende da condição nutricional, mas também das reservas energéticas e vitamínicas maternas. A partir do segundo trimestre, os fatores externos maternos vão passar a ter contribuição direta sob a condição nutricional do feto. $\mathrm{O}$ ganho de peso adequado, a ingestão suficiente de energia e nutrientes, o fator emocional e o estilo de vida serão determinantes para o crescimento e desenvolvimento fetal adequado.

A obrigação alimentar possui intenso caráter social, vez que contribuem diretamente para a formação, sobrevivência e integridade da pessoa humana, revelando verdadeira materialidade dos princípios fundamentais constitucionais. A Lei $\mathrm{n}^{\circ} 11.804$, que trata dos alimentos gravídicos, concede à gestante o direito de demandar ação de alimentos durante a gravidez, exigindo do indicioso pai a responsabilidade ao pagamento. Um dos objetivos da referida legislação é tutelar o nascituro, atentando-se para as necessidades da gestante, para que, consequentemente, o feto venha a se desenvolver e nascer saudável. Ocorre que quando se trata de mulheres em situação de rua, saber quem seria o pai e demanda-lo torna a situação ainda mais complexa e dificultosa. Muitas vezes esse genitor não possui, assim como a mãe, condições de provimento. Outros casos, a mãe realmente não tem conhecimento de quem seria o pai. Esse cenário marginaliza ainda mais esse público feminino, que se encontra desemparado legalmente, por uma lei inaplicável e inacessível, tornando-as cada vez mais invisíveis na sociedade e completamente desamparadas.

Diante disso, é necessário que o Estado e a sociedade passem a adotar medidas para que essas mulheres tenham voz e acolhimento, com o mínimo de garantias asseguradas. "A realização de ações educativas e assistenciais, no decorrer de todas as etapas do ciclo gravídicopuerperal, é 
muito importante, pois é no pré-natal que a mulher deverá ser mais bem orientada para que possa viver o parto de forma positiva e ter menos riscos de complicações no puerpério" (DUARTE; ALMEIDA, 2014).

A proteção à gestante é reflexa ao nascituro e, portanto, interesse do Estado, visto que proporcionar-lhe um nascimento saudável acarretará, mais tarde, na prevenção de um indivíduo físico, social e moralmente restrito, vez que o amparo do ser humano desde seu estágio fetal, implica em segurança de vida sadia.

\section{CONCLUSÃO}

Diante do cenário apresentado, tem-se que é impossível falar em nascituro e garantia de seus direitos sem voltar-se para gestante e seu bem estar. Os direitos da mulher grávida estão intimamente ligados aos do nascituro. É através dela que este ente concebido, porém não nascido, desenvolve-se e pode pleitear suas garantias.

Dessa forma, um olhar para a gestante é imprescindível, especialmente nos casos de mulheres em situação de rua, cuja vulnerabilidade e invisibilidade é manifesta, agravada com a pandemia da Covid-19, impactando diretamente no desenvolvimento do nascituro e no respaldo dos seus mais basilares direitos.

O Brasil não conta com dados oficiais precisos sobre a população feminina gestante em situação de rua. Essa ausência de informação prejudica a implementação de políticas públicas voltadas para este contingente, reproduzindo a invisibilidade social da população de rua no âmbito das políticas sociais e marginalizando ainda mais esse público da sociedade e do acesso aos serviços sociais.

Se o acesso da população em situação de rua a serviços de saúde e assistência social já é limitado e encontra problemas usualmente, em contexto de crise, como a vivenciada atualmente na pandemia do Corona Vírus, esses obstáculos são acentuados em razão, por exemplo, da redução da oferta de serviços públicos e da mudança dos atendimentos presenciais para remotos, dificultando ainda mais o atendimento da população necessitada. 
Ainda no contexto de pandemia, embora o governo federal tenha aprovado auxílio emergencial a ser pago para pessoas de baixa renda que estejam ocupadas em atividades informais durante a pandemia do Corona Vírus, referida medida acaba, na maioria dos casos, não atingindo as pessoas em situação de rua, que enfrentam dificuldades adicionais e, por vezes, intransponíveis, como ausência de documentos pessoais, que acabam impossibilitando o cadastro para recebimento do referido auxílio. Sem falar que estão expostas a outros tipos de riscos que nem o valor e nem a natureza desse recurso seriam capazes de suprir (NATALINO; PINHEIRO, 2020; ISONI, 2020; apud IPEA, 2020).

Essa mulheres, gestantes, além de todos esses problemas sociais, como insuficiência das vagas de abrigamento, obstáculos para acesso às transferências de renda, especialmente vinculadas ao acesso à informação, documentação e tecnologia, falta de acesso aos serviços de saúde e à alimentação adequada, enfrentam, ainda, dificuldade de testagem e tratamento ante a possibilidade de contaminação pelo vírus Covid-19.

Necessário, portanto, tendo como norte a efetivação da Lei n ${ }^{\circ} 7.053$ de 2009, que visa a proteção de pessoas em situação de rua, uma mudança de mentalidade e o direcionamento dos olhares sociais e públicos para essa população tão desamparada. É preciso que, inicialmente, haja o reconhecimento dessas pessoas para, então, serem adotadas medidas de proteção e salvaguarda das mesmas.

A partir disso é que o Estado deve se debruçar na implementação de políticas públicas, as quais precisam ser próprias para gestantes em condição de rua, em virtude de especificidades inerentes à gestação. Deve-se contemplar a realização de exames e acompanhamentos psicológicos e médicos, possibilitando a essas mulheres o acesso aos serviços de saúde e proteção básica de forma contínua, bem como medidas emergenciais de abrigamento e alimentação e oferta de equipamentos públicos de higiene.

É preciso construir novas formas de atuação junto a essa população, tendo como eixo atividades cotidianas e estratégias de vida adequadas ao ritmo e à dinâmica de vida dessas mulheres em condição de rua, no intuito de tirá-las dessa situação que ameaça tanto à saúde e 
proteção da criança, quanto ao próprio direito da mãe em cuidar de seu filho. Essa criança deve ser fator motivacional para elas saírem das ruas e planejarem um futuro.

A inadequada alimentação no cenário de rua, ademais, requer estratégias de adequação significativas em redução de danos e educação em saúde para esse público, que muitas vezes é usuário de substâncias psicoativas, apresentando limitada compreensão da importância de sua saúde e da vida em gestação.

É preciso, portanto, que os olhares se voltem para essas mulheres, de maneira a assistilas, informando-as de seus direitos e deveres como mães, atendendo às necessidades de saúde, física e/ou psicológica, e de higiene, tão importantes no período gravídico e que se fazem essenciais diante da pandemia enfrentada. É preciso que elas tenham fornecidas suplementações alimentares, garantindo-lhes um aporte energético mínimo para uma gestação saudável. Nesse sentido, faz-se essencial a implementação de medidas mais definitivas para esta população, de maneira a ser contemplada pela atenção prioritária dos governos. Fundamental, ademais, é a união das instituições públicas responsáveis pela tutela desses vulneráveis, como o Ministério Público e a Defensoria Pública, de maneira a analisarem a efetividade das políticas públicas destinadas a atenderem essas mulheres, intermediarem o diálogo com instituições de acolhimento e assistenciais, buscarem o comprometimento de metas específicas e a celeridade no atendimento a mães nessa situação de forma individualizada, para que tenham preservados seus direitos e os das crianças.

É preciso aumentar o cuidado e a proteção social desse público específico, de modo a construir um raciocínio político adequado, buscando compreender que a garantia de sua dignidade é reflexa a do nascituro. É preciso que essas mulheres sejam percebidas, vistas. Que sejam e sintam-se verdadeiramente acolhidas, amparadas e seguras do atendimento que recebem, para que essa invisibilidade seja quebrada e elas possam se sentir parte da sociedade. São esses sentimentos de cuidado, proteção e importância que farão com que haja engajamento e continuidade nos atendimentos a elas desempenhados, possibilitando, dentro do possível, um período gestacional sadio e assistido, que resulte em um nascituro saudável, com direitos da 
personalidade integralmente respeitados, para que possa a nascer com vida e vir a integrar o seio social.

De nada adianta lutar pelos direitos do concepturo, se a responsável pelo desenvolvimento dessa vida está desamparada. O período em que o feto permanece no ventre materno é etapa primordial da vida humana, devendo ser integralmente resguardado pelo direito naquilo que disser respeito ao nascimento com vida daquele ser, de maneira a propiciar a eclosão da pessoa natural, que só é possível se a gestante for protegida. Sem isso, torna-se irrelevante falar em direitos do nascituro.

\section{REFERÊNCIAS}

ALBERTON, Alexandre Marlon da Silva. O direito do nascituro a Alimentos. Rio de Janeiro: AIDE, 2001.

ALMEIDA, Diana Jenifer Ribeiro de; QUADROS, Laura Cristina de Toledo. A pedra que pariu: narrativas e práticas de aproximação de gestantes em situação de rua e usuárias de crack na cidade do Rio de Janeiro. Revista Pesquisas e Práticas Psicossociais, v. 11, n. 1, p. 225-237, 2016.

ALVES, Grazielle da Silva. O direito postulatório do nascituro. Escola da Magistratura do Estado do Rio de Janeiro. Rio de Janeiro, 2016. Disponível em: < https://www.emerj.tjrj.jus.br/paginas/rcursodeespecializacao_latosensu/direito_processual_civil/e dicoes/n5 2016/pdf/GrazielledaSilvaAlves.pdf>; Acesso em: 31/03/2021;

ARAÚJO Ana Thereza Meirelles; FILHO, Rodolfo Pamplona. Tutela jurídica do nascituro à luz da Constituição Federal. Revista Magister de direito civil e processual civil. $18^{\mathrm{a}}$ edição, p. 33-48. Porto Alegre, 2007. Disponível em: http://www.andt.org.br/f/20132828_ANDT_artigo_tutelanascituro_Rodolfo.pdf>; Acesso em: 20/03/2021;

CASALI, Nely Clopes. O nascituro no ordenamento jurídico brasileiro. Revista Jurídica Cesumar - v.4, n. 1, 2004. Disponível em: file:///C:/Users/USER/Downloads/363Texto\%20do\%20artigo\%20-\%20Arquivo\%200riginal-1482-1-10-20071018.pdf; Acesso em: 16/03/2021;

COSTA, Bruno A. A falta do que comer. The News. Brasil. 15 de abril de 2021. Disponível em: https://thenewscc.com.br/2021/04/15/a-falta-do-que-comer/>. Acesso em: 15/04/2021; 
COSTA, Samira Lima da et al. Gestantes em situação de rua no município de Santos, SP: reflexões e desafios para as políticas públicas. Julho - Setembro, 2015. Disponível em: < https://www.scielosp.org/article/sausoc/2015.v24n3/10891102/\#: :text=Assim\%2C\%20no\%20caso\%20da\%20gesta\%C3\%A7\%C3\%A3o,risco\%20para\% 20m\%C3\%A3e\%20e\%20beb\%C3\%AA; Acesso em: 31/03/2021;

CHAVENCO, Arlete Aparecida; OLIVEIRA, José Sebastião de. Da Tutela dos Direitos do Nascituro e a controvertida questão do início de sua Personalidade. Revista Jurídica Cesumar - Mestrado, v. 12, n. 2, p. 657-677, jul./dez. 2012.

DINIZ, Maria Helena. O Estado atual do biodireito. $2^{\circ}$ edição. São Paulo: Saraiva, 2002.

DUARTE SJH, ALMEIDA EP. The role of the nurses family healt program in prenatal care. Rev. Enferm Cent O Min [Internet]. 2014, Jan/Apr; 4(1):1029-35. Disponível em: http://www.seer.ufsj.edu.br/index.php/reco m/article/view/137/577; Acesso em: 22/03/2021;

GONÇALVES, Carlos Roberto. Direito Civil Brasileiro. Parte Geral. 12a edição. São Paulo: Saraiva, 2014.

IPEA. (s/a) População em Situação de Rua. Disponível em: < https://www.gov.br/mdh/ptbr/navegue-por-temas/populacao-em-situacao-de-rua/populacao-em-situacao-derua\#: :text=Conforme\%20estimativa\%20realizada\%20pelo\%20IPEA,situa\%C3\%A7\%C3\%A30 \%20de\%20rua\%20no\%20Brasil; Acesso em: 06/04/2021;

IPEA. (s/a) População em situação de rua em tempos de pandemia: um levantamento de medidas municipais emergenciais. Nota técnica n. 74. Junho, 2020. Disponível em: https://www.ipea.gov.br/portal/images/stories/PDFs/nota_tecnica/200610_nt_74_diset.pdf;

Acesso em: 06/04/2021;

LOMEU, Leandro Soares. Alimentos Gravídicos: Aspectos da Lei 11.804/08. IBDFAM, 2008. Disponível em: < https://ibdfam.org.br/artigos/467/novosite>; Acesso em: 22/03/2021;

MEDICINA UFMG, 08.06.2020. Maternidade nas ruas se agrava com pandemia. 2020. Disponível em: <https://www.medicina.ufmg.br/maternidade-nas-ruas-se-agrava-com-pandemia/; Acesso em: 31/03/2021;

MINISTÉRIO PÚBLICO DO PARANÁ, 29/08/2019. (2019) Ministério Público do Paraná faz trabalho de acompanhamento do atendimento de órgãos públicos a gestantes em situação de rua em Curitibar em:

http://www.crianca.mppr.mp.br/2019/08/21852,37/Ministerio-Publico-do-Parana-faz-trabalhode-acompanhamento-do-atendimento-de-orgaos-publicos-a-gestantes-em-situacao-de-rua-emCuritiba.html; Acesso em: 31/03/2021; 
SÃO PAULO (Cidade). Secretaria Municipal de Assistência Social; FIPE - FUNDAÇÃO INSTITUTO DE PESQUISAS ECONÔMICAS. Censo dos moradores de rua da cidade de São Paulo: relatório executivo. São Paulo, 2000.

SUAREZ, Joana. (2019). Recife: com um bebê e sem documentos. Publicado em 09/ 09/ 2019. Disponível em: < https://apublica.org/2019/09/os-dias-de-iriana-nas-ruas-de-recife-com-umbebe-e-sem-

documentos/\#: :text=Recife\%20fez\%20um\%20censo\%20em,gestantes\%20\%E2\%80\%93\%20ent re\%20elas\%2C\%20Iriana.; Acesso em: 22/03/2021;

VIEIRA, M. A. C.; BEZERRA, E. M. R.; ROSA, C. M. M. População de rua: quem é, como vive, como é vista. 3. ed. São Paulo: Hucitec, 2004. 